\title{
Online science videos: an exploratory study with major professional content providers in the United Kingdom
}

\section{Carmen Erviti and Erik Stengler}

\begin{abstract}
We present an exploratory study of science communication via online video through various UK-based YouTube science content providers. We interviewed five people responsible for eight of the most viewed and subscribed professionally generated content channels. The study reveals that the immense potential of online video as a science communication tool is widely acknowledged, especially regarding the possibility of establishing a dialogue with the audience and of experimenting with different formats. It also shows that some online video channels fully exploit this potential whilst others focus on providing a supplementary platform for other kinds of science communication, such as print or TV.
\end{abstract}

Keywords

Popularization of science and technology; Science and media; Visual communication

Online video is one of the most popular content choices for Internet users. According to Cisco [2014], video traffic was, in terms of data, $66 \%$ of all consumer Internet traffic in 2013 and it is predicted to be $79 \%$ by 2018 .

Online video is extensively used for instructional purposes and various authors have analysed this use in recent years [e.g. Pace and Jones, 2009; DeCesare, 2014; Cooper and Higgins, 2015]. Morain and Swarts [2012] proposed a methodology to analyse instructional online video, focussing on sounds, images and texts, the rhetorical work and the information design of a sample of videos.

The use of online video within the academic community is also growing as a means of peer-to-peer communication, and Kousha, Thelwall and Abdoli [2012] studied YouTube videos cited in published academic research.

Here we will focus on the use of online video in public science communication. Online video is considered an accessible format to disseminate scientific information to the general public [Thelwall, Sud and Vis, 2012; Young, 2011]. It is widely known that users increasingly search for information in video format directly, using online video sites such as YouTube as search engines, and various studies have analysed the role of YouTube as an information source on particular scientific topics: Pandey et al. [2010], on the H1N1 influenza pandemic; or Burton [2008], on neurological knowledge. 
YouTube is a website where users can upload, view and share online videos. It was created in 2005 by Chad Hurley, Steve Chen and Jawed Karim, former employees of the e-commerce company PayPal. A year later, the site was purchased by the American multinational Google. At the moment, YouTube is the third most visited site after Google and Facebook [Alexa, 2015]. Viewing hours per month on YouTube increase by $50 \%$ every year and 300 video hours are uploaded to YouTube each minute [YouTube, 2015]. All this gives us an idea of the power of YouTube: 'The YouTube clip has become the dominant form of early twenty-first-century videography' [Lister et al., 2009, p. 227].

Two kinds of content can be distinguished on YouTube: user-generated content (UGC) and professionally generated content (PGC). As Kim [2012] explained, professional content is growing in volume compared to user-generated content, and the website is becoming institutionalized, and 'cannot be thought of solely as a revolutionary medium because of its being influenced by traditional agents (i.e. network broadcasters and TV audiences), content (i.e. program genre and style) and institutions (i.e. copyright and advertisements)' (p 53). However, 'user-generated content is significantly more popular' [Welbourne and Grant, 2015].

According to Pace [2008], 'YouTube content can be best understood as stories' [p. 213] and, in fact, it has 'typical elements of a story: plot, character, structural pattern, and organization, expressions (as the chosen visual elements)' [p. 222]. Lister et al. [2009] compared the genres on YouTube and on television and concluded:

All the genres are at once similar to the genres we are familiar with from TV culture but at the same time entirely unexpected and unpredictable, fresh with the imprint of living breathing individuals rather than the seamless patina of corporate product [p. 229].

The YouTube Creator Playbook [YouTube, 2013] provides support for "produsers" (a blend of the morphemes and the meanings of the words "producers" and "users"; Bruns [2007]) to develop a cohesive channel strategy with the aim of reaching the widest audience possible and to build a community around the channel.

The key objective is to catch the viewer's attention in the first seconds of each video. In conjunction with that, promotion is essential and YouTube contents have to be made accessible through other sites, mainly social media. Many of these sites then extend YouTube's own community building possibilities. Analysing such video-sharing communities, Huang, Chen and Wang [2012] mention that in them, people want to gain reputation within a group: perceptions of the quality of the content and empathy affect expectations of control, inclusion, and affection.

Welbourne and Grant [2015] provide the first overview of science communication on YouTube, analysing the influence of content-related aspects on the popularity of online videos. Through a content analysis of 390 online science communication videos they identified that UGC is significantly more popular than PGC, despite there being more PGC available, and that the presence of a regular presenter and a fast pace also positively correlate with popularity. 
More recently, Trotha, Morcillo and Czurda [2016] studied 200 UGC and PGC online videos in order to identify a set of typologies and different levels of complexity. They found a strong storytelling expertise over a variety of genres and a clear indication of a growing professionalism in their production. This confirms that the need stated by Obrist et al. [2015] 'for good storytelling through visual means remains strong as the lines between traditional television consumption and online video are blurring.' [p. 35].

In this paper we intend to complement these studies from a different angle, by offering insights from in-depth interviews with the people behind 8 of the most viewed PGC YouTube channels from the UK that communicate science to the public.

Objective

We present a study on PGC UK science communication YouTube channels, with the aim of exploring the motivations of the institutions or individuals behind them, the differences and similarities regarding channel management and video production, and how they see online video as a science communication tool.

Methods

To address these research questions, we decided to use qualitative (semi-structured) interviews. Semi-structured interviews were chosen as our data collection method, since it was expected that the information obtained from each source would vary significantly in scope and complexity [Veal, 2011]. Also, semi-structured interviews allowed us to ensure that the research questions are addressed, while giving the interviewees sufficient freedom to bring up free associations between different topics, refer to motivations and generally provide data that is extensive and rich in detail [Howitt, 2013, pp. 57, 66].

We first selected the most subscribed and the most viewed UK Science \& Technology channels through VidStatsX. From the list of the top 100 obtained we excluded the technology channels which focus on commercial products. At the cut-off date of the 8th of October 2014 the remaining top channels were:

- Vsauce (1st most subscribed and 2nd most viewed),

- Numberphile (20th most subscribed and 53th most viewed),

- New Scientist (55th most viewed),

- Periodic videos (41th most subscribed)

- Sixty Symbols (53th most subscribed).

Since four of these five channels are very similar in that they are run by freelance "youtubers", and three of them are run by the same person, and given the exploratory nature of this study, we decided to extend the sample to other UK YouTube channels in order to have representation from different types of institutions that also produce PGC online science communication videos. In particular, we included the following: 
- Nature Video, by Nature magazine.

- BBC Earth and Earth Unplugged, by BBC Earth.

- The Royal Institution YouTube channel.

No VidStatsX data are available for these channels as they were not among the top 100 for views or subscriptions at the time. We include number of subscribers for all channels in table 1, for comparison.

Table 1 shows a summary of the interviews conducted for this study, in which we interviewed all but one of the intended candidates, as we were not able to contact Michael Stevens from Vsauce. All interviews were conducted face-to-face at the interviewees' workplaces, recorded, and with both authors present and taking notes.

Table 1. YouTube channels considered in this study and persons interviewed.

\begin{tabular}{|c|c|c|c|c|}
\hline YouTube Channel & $\begin{array}{c}\text { Subscribers } \\
(7 / 11 / 2014)\end{array}$ & Created & Interviewee & $\begin{array}{l}\text { Date } \\
\text { Interviewed }\end{array}$ \\
\hline Periodic Videos & 499158 & $6 / 6 / 2008$ & \multirow{3}{*}{$\begin{array}{l}\text { Brady Haran, Freelance } \\
\text { filmmaker, in } \\
\text { collaboration with the } \\
\text { University of } \\
\text { Nottingham. }\end{array}$} & \multirow[t]{3}{*}{$26 / 9 / 2014$} \\
\hline Sixty Symbols & 424566 & $13 / 2 / 2009$ & & \\
\hline Numberphile & 1066298 & $15 / 09 / 2011$ & & \\
\hline New Scientist & 117373 & $27 / 11 / 2006$ & $\begin{array}{l}\text { Sandrine Ceurstemont, } \\
\text { Online multimedia } \\
\text { producer. }\end{array}$ & $4 / 11 / 2014$ \\
\hline Nature & 76662 & $7 / 11 / 2008$ & $\begin{array}{l}\text { Charlotte Stoddart, } \\
\text { Head of Multimedia. }\end{array}$ & $2 / 10 / 2014$ \\
\hline BBC Earth & 393820 & $24 / 2 / 2009$ & \multirow{2}{*}{$\begin{array}{l}\text { Charlotte Jones, BBC } \\
\text { Earth Executive Producer. }\end{array}$} & \multirow[t]{2}{*}{$21 / 11 / 2014$} \\
\hline Earth Unplugged & 289048 & $2 / 11 / 2012$ & & \\
\hline Royal Institution & 102454 & $16 / 9 / 2009$ & $\begin{array}{l}\text { Ed Prosser, } \\
\text { Multimedia Producer. }\end{array}$ & $4 / 11 / 2014$ \\
\hline
\end{tabular}

Table 2 shows a checklist of topics to be covered in the conversations. Notes were taken and the interviews were recorded as a backup and to check instances of unclear wordings for which it would have been inappropriate to interrupt the interviewees. The checklist consisted of 18 items that combined, allowed us to collect data to address the research questions. The major themes probed being the following: Aims and objectives of setting up and curating a YouTube channel; channel management; characteristics and popularity of videos; and the role of online videos in science communication.

The subsequent analysis was carried out as a thematic analysis, as the primary intention is not to test a theory but to descriptively form a picture of online video science communication [Howitt, 2013]. Coding followed a data-led approach within the initial parameters set by the research questions. 
Table 2. Schedule for the semi-structured interviews.

\begin{tabular}{|r|l|}
\hline & Interview question \\
\hline 1 & When and why was it decided to open the channel(s) on YouTube? \\
\hline 2 & What are the aims, what audiences are targeted? \\
\hline 3 & $\begin{array}{l}\text { How is the YouTube channel organized and managed, e.g. in terms of sec- } \\
\text { tions, contents, frequency of upload? }\end{array}$ \\
\hline 5 & Who are the online video producers? Is production in-house or outsourced? \\
\hline 6 & $\begin{array}{l}\text { What is your relationship with subscribers and users of the YouTube chan- } \\
\text { nel? }\end{array}$ \\
\hline 7 & Any other comments on channel management? \\
\hline 8 & $\begin{array}{l}\text { Are YouTube statistics monitored and strategies followed to position the } \\
\text { videos? }\end{array}$ \\
\hline 9 & $\begin{array}{l}\text { What is your level of Satisfaction regarding the objectives that are being } \\
\text { achieved through videos on YouTube? }\end{array}$ \\
\hline 10 & $\begin{array}{l}\text { Why do you think that the online video is a good tool to communicate sci- } \\
\text { ence? }\end{array}$ \\
\hline 11 & What features can make a video popular? \\
\hline 12 & $\begin{array}{l}\text { What do you think about the accuracy of science online videos? Are there } \\
\text { lot of amateurs? Do you consider it a problem, for example in the case of } \\
\text { health information? }\end{array}$ \\
\hline 13 & Do you follow the advice of the YouTube guide? \\
\hline 14 & How many people are involved in your YouTube channel? \\
\hline 15 & What do you consider to be your channel's distinctive feature? \\
\hline 16 & $\begin{array}{l}\text { What is your most watched science video? Why do you think made it so } \\
\text { popular? }\end{array}$ \\
\hline 17 & $\begin{array}{l}\text { What are your project and expectatios for future developents of your dis- } \\
\text { semination of online video? }\end{array}$ \\
\hline
\end{tabular}

We have grouped the responses obtained in the interviews according to the themes established above.

Aims and target audiences of the online science channels. In all cases, the respondents indicated that their goal was to reach a wide audience around the world, but there were other more specific aims in some cases.

The journalist Brady Haran was passionate about science, and wanted to share this passion with the public, making videos that people really want to see.

One of the reasons we have enjoyed some success is because of this attitude, this sort of non-corporate attitude, it is a generalistic attitude [...] Your first thing, what you should always be thinking, is what would the audience like, because if you're doing that then you're probably coming at it from a better angle.

For the magazines Nature and New Scientist, videos worked as a complement to their publications. In the case of Nature, the Head of Multimedia, Charlotte 
Stoddart, appreciated the chance 'to just tell people about the research we publish' through moving images when the story is visual.

Many of the research papers that Nature publishes are not particularly visual, the story is not particularly visual, but for some things, really, the only way to understand what's going on, for the researchers as well as for the public, is to see it.

Charlotte Stoddart explained that further aims for Nature were to encourage journalists to report on their articles and improve Nature's brand recognition.

The Multimedia Producer at New Scientist, Sandrine Ceurstemont, valued the opportunity to communicate science showing and telling stories in a visual way: 'In certain cases, video is the more attractive way to convey certain stories, because you can describe some things in words, but you just see the video and, right away, you get the point.'

For the Executive Producer at BBC Earth, Charlotte Jones, 'establishing the brand of The Earth' in a very competitive market was decisive to create multiplatform content. They needed a clear brand for the public to engage with BBC content, avoiding confusion with Discovery channel, especially in the USA, where it broadcasts BBC content. The BBC Earth YouTube channel put together all the highlights of their television programs in short videos, so their natural history audience were able to access them online. More recently, they launched Earth Unplugged, in collaboration with Google, to catch new audiences and continue to lead the natural history market, creating a community around the channel.

The Multimedia Producer at The Royal Institution of Great Britain, Ed Prosser, emphasized education and engagement with science as the main important objective: 'Increasing the amount of science content that's on YouTube and presenting it as something that's not necessarily a separate thing from culture. [...] What we want to show is that science can be part of contemporary culture.'

Most of the interviewees said that their YouTube channels reached different audiences than their official websites and mentioned rather broad and generic categories regarding the audiences they aim and expect to reach.

Charlotte Stoddart indicated that the audience of the website of Nature is mainly working scientists, PhD students and scientific literature readers, but it was not exactly the same with their YouTube channel, where around the $60 \%$ of the views are a direct result of the videos being embedded in other websites, mainly newspapers and television stations, and from sharing on social media. Viewers of the YouTube platform were also more international. The Multimedia Producer at New Scientist also explained that their audience was primarily the same as the print magazine, but new audiences were being attracted through YouTube.

The only response with a clear and specific audience segment was given by Charlotte Jones regarding Earth Unplugged. BBC Earth discovered a gap in their audience between ages 16 and 34, so they decided to create original contents through this YouTube channel with this audience in mind. Charlotte Jones 
recognized that young people were not attracted by standard documentaries about natural history, because they thought that they were boring. According to her, 'It's about working out how to reach different ages in a language they are used to, and the YouTube language is how this audience segment consumes content.'

All the interviewees were satisfied with the progress of their channels on YouTube and they considered that their objectives were being achieved.

YouTube channel management and monitoring. There is a multimedia team (four people) to make videos and podcasts at Nature, and only one person for $\mathrm{New}$ Scientist, The Royal Institution and Brady Haran's channels. The BBC had at some point up to 25 people creating content for BBC Earth and Earth Unplugged, the number being currently variable and lower. Earth Unplugged is considered as a platform where young professionals can gain experience in production before going on to TV jobs. All of the interviewees indicated that they work in close in collaboration with scientists to create the stories. Nature and New Scientist use footage provided by the research scientists themselves.

The cost of producing online videos was not high if compared to television, but all interviewees mentioned the need to get funding. For Charlotte Jones (BBC), YouTube was a means to establish a conversation with people in real time that would inform production, so it is difficult to fix contents and set a budget:

We learned how sometimes cheap content can be really powerful and engaging. [...] The brilliant thing about YouTube is that when it's not working, you just change it, and it's not a big problem.

All the interviewees agreed that the frequency of new videos was important to communicate with the YouTube users. The frequency depended on the priorities of each channel. In the case of Nature, there was not a policy to publish one video every week, because the magazine looked for quality -good stories appropriate for video-, over quantity, so they upload an average of three or four videos a month. In contrast, New Scientist uploads one video per day. The rest of the "produsers" make one video a week. The Royal Institution even considered the day of the week to upload their contents: for their video project called ExpeRimental, which consisted on a series of short films for families with little children, they uploaded new videos on Thursdays or Fridays, because they thought that the families could do the experiments at weekends.

The respondents also agree about the relevance of the comments from viewers on YouTube. Although not all of them had enough time to read and answer them, they all acknowledged that comments help create a community of users around a video, because users get involved in conversations among themselves. Sometimes questions from the public were followed-up with new videos. Here the BBC stands out by assigning a specific role of "community manager" within the team, with the remit of closely monitoring the conversations and a direct involvement with the formed communities.

There was a certain degree of monitoring of the uploaded videos, but hardly beyond using analytics and statistics provided by the platform itself. They were 
interested in this in order to improve their video content and their impact. In some cases, there was an orientation toward quality: for Nature, knowing in which other websites their videos are embedded was more important than the number of viewers and subscribers.

Style and characteristics of online science videos. We asked each interviewee about the style of their videos and distinctive features of their productions.

The common answer regarding style was that videos are short and with interesting stories, but with hardly any other set parameters regarding style, with the exceptions of Brady Haran to a certain extent and BBC Earth. Brady Haran's videos have a homogeneous style in that he mainly makes interview-based videos, trying to show 'real places with real people', so the viewers can listen directly to the experts. BBC Earth Unplugged have a set of much more precise style guidelines with a clear purpose of giving their YouTube content a specific personality: they consider that videos are a conversation with the community and try to create an intimate relationship. Presenters look into camera, shots are close-up, clips start with a question, with the answer in the middle and a clear prompt for the conversation to continue with the community at the end.

Sponsored videos from Nature had their particular style, but the magazine did not set the style. Sometimes, clips belonging to a series on a particular topic follow a similar format, such as for Nature's videos on neurosciences. For the Royal Institution, specific projects - such as ExpeRImental - have their own style and branding. Otherwise only intros and outros are kept the same. Sandrine Ceurstemont mentioned that at New Scientist they take the opportunity to experiment with different formats and styles.

In general, all channels appreciated the possibility of using humour on online videos.

Brady Haran considers that giving a voice to the experts themselves with questions that the viewer would have liked to ask is the distinctive feature of his videos.

Nature and New Scientist make videos to illustrate articles, so they consider that early access to research and authors and the use research footage are their distinctive feature, but we also found that regarding research, the Royal Institution places itself at the other end of the spectrum, valuing precisely the fact that their videos are not being linked to specific research outputs.

The institution's heritage and their archives are important for BBC Earth and the Royal Institution because they have a wealth of valuable materials. For example, The Archive Collection from the Royal Institution includes classic talks, lectures and demonstrations presented by some of the world's leading scientists, from the fifties until today, and many events have not been seen since they were first staged.

What makes a video popular? As expected, no one claimed to know the key for success on YouTube, but some ideas were suggested: making videos that people would be willing to share; short, novel, humorous videos; interesting and quirky subjects; visually amazing images. Common to most answers was that showing content that has not been seen before is essential. 
It was also suggested by Brady Haran that a distinction is needed between sustained popularity and a single video becoming popular. 'In terms of making a channel consistently popular', his key ideas are:

Making good videos all the time, thinking about the audience, with likeable people; good production quality is important as well as interesting topics, consistent uploading, making videos regularly. To make a video go crazy is something different and harder to know. If I knew how to do that perfectly, I would do it all the time.

In any case, a social media strategy is needed to widely disseminate a video through the Internet, as Ed Prosser explained:

I think one of the misconceptions of viral videos is that they just go viral on their own, which is not really the case. Most popular videos on YouTube have had the authors of those videos spending one, two days emailing, tweeting, facebooking, posting that video in as many places as possible and, in that sense, that social media sharing element is just as important as the time it took them to shoot the video.

Charlotte Jones did not give a direct answer, but the examples she provided showed that at BBC Earth they identified collaboration with different, sometimes competing, channels as a source of shared and therefore wider audiences, which helped clips to go viral.

Online videos as a tool to communicate science. For the producers of multimedia content of Nature, New Scientist and the Royal Institution, online videos were a good tool to communicate science for some but not all scientific stories. Charlotte Stoddart, from Nature, stated that 'video conveys emotion in a way that a quote or a [written] story wouldn't convey', although 'sometimes, I think, if the story is a very complicated one, with lots of numbers, for example, or very subtle arguments, then actually it's better to communicate it in a carefully written piece or maybe in a graphic way.'

On the other hand, the head of multimedia of the Royal Institution considered that online video was a remarkably good tool to reach those so-called digital natives (born after 1995) and millennials (born between 1980-1995).

\footnotetext{
Younger generations, my generation, we've grown up with computers and technology. Video is used now more than they would necessarily read. When they have a problem or they want to find something else, recent research suggests, instead of googling for text articles, they use YouTube to look for the answer. Video is becoming much more commonplace and central. People have phones, tablets, smart televisions; they can watch YouTube on all of those.
}

As mentioned before, this audience segment was specifically targeted by the BBC with Earth Unplugged, and as Brady Haran said, nowadays 'people expect to be able to watch', so online video is powerful to disseminate scientific information to an audience accustomed to visual online communication. 
All interviewees commented extensively on the differences between online videos and TV, agreeing in one way or another that unlike in television, where the duration of programmes and the time available for shooting is fixed, there are no 'artificial' time restrictions for online contents: online videos can be as short or as long as their content requires. Online video also offers the possibility of further experimentation. The interviewees noted that people's expectations were different in the case of online videos. 'I think style is a big thing in online video. [...] Online video is more experimental', Sandrine Ceurstemont said. Brady Haran remarked that the role of TV could become to be a launch-pad or showcase for online content that viewers can then follow-up on the web. Charlotte Jones went in the opposite direction suggesting that online video can become a platform for people and content, that after success on the web can then be selected to appear on TV, as has already happened.

Finally, all interviewees agreed that ever easier access to video production tools has brought about problems with scientific accuracy, as almost anyone can nowadays create and post a video on a scientific topic. However, in general, all interviewees indicated that this concern was of minimal importance because they understood that some of the biggest science channels on YouTube were made by institutions or individuals with a scientific background, and a self-selection regarding trust ends up dissipating this problem. This was also the position of Ed Prosser, from the Royal Institution, but he was the only one to also mention the potential danger of inaccurate science being circulated regarding health issues.

The YouTube channels of our study are found to be very diverse in nature and scope, with aims as generic as widening engagement with science and as specific as establishing a brand, and target audiences ranging from the widest possible public to readers of specific articles in a printed journal. This is already indicating that online science videos are not a homogeneous science communication tool, a conclusion also reached by Trotha, Morcillo and Czurda [2016].

None of the factors found by Welbourne and Grant [2015] to influence the popularity of online science communication videos was mentioned by our interviewees: They did not allude to UGC at all nor were the role of the presenter and the pace mentioned as choices made for the sake of popularity, even though these are features that are certainly present and taken into consideration in their videos.

Responses that are common to three or more interviewees include: some limited monitoring of viewing stats; not having a set style; first hand access to researchers and experts; the fundamental role of social media to promote viewings; freedom in production from time and budget constraints, thus being able to experiment; and the need for striking, unusual, never-seen-before contents.

The last point has been considered in other studies in more detail. Cha and Chan-Olmsted [2012] in their analysis of the perception of substitutability between online video and television, identified that 'online video venues need to focus on acquiring content that provides consumers with opportunities to learn something new and with the latest news events' [p. 273], as a way to learn efficiently, in a society where timeliness and speed are growing in demand. But, beyond that, and 
according to Pirouz et al. [2015], offering new, striking and unusual content is successful in engaging viewers because of the emotional reaction it elicits. They looked at a range of attributes and focused on three themes that create emotional reactions: novelty, incongruity and hyperbole, finding that overall 'emotionally surprising videos generated liking and views more than any kind of specific content element we studied' [p. 86]. Furthermore, if the 'goal is to get viewers' attention by surprising them, they have two good choices: Show them something they have never seen before, or show them two things they are familiar with but in an original, juxtaposed way - to "make it new," as the poet Ezra Pound once advised.' [p. 87]. Such ideas were expressed in different ways by all our interviewees, and novelty is indeed a primary factor of motivation for audiences to engage with science communication also in other formats, such as live public lectures [AbiGhannam et al., 2016].

An interesting case concerns the theme of building communities and establishing a dialogue with the audience. Whilst in one way or another all interviewees appreciate the possibility of interacting with the public, it seems that in only one case this idea is seen through, permeating all aspects of the online science video channel: building a community and sustaining dialogue with viewers informs all aspects of the way BBC Earth's channels are managed and their videos are produced. It is followed at a distance by the Royal Institution, who also seems to pay significant attention to these aspects.

Cha and Chan-Olmsted [2012] analysed in detail the substitutability between online video and television. They argued that a key aspect of video consumption is the realisation of the "functional uniqueness" of each medium. In particular, their paradoxical result that non-users of online video are more likely than users to perceive online video as a substitute for TV led them to conclude that in order to attract more and more consumers and to convert non-users of online video platforms into users, creators of online video platforms should develop and establish further their functional uniqueness' [p. 273]. The specific goals of viewers who seek this functional uniqueness include, according to these authors, seeking information, entertainment, and, interestingly, social interaction. Our study shows that the BBC has, through the channel BBC Earth Unplugged, recognised and embraced the need to address these goals, and specifically the latter, and therefore fully grasped the whole new dimension that the web 2.0 adds to science communication through video, and how radically different it is from TV.

In fact, the element of interactivity and viewer feedback has been and still is an important research field in the context of the changing viewing and engagement habits of television, and the experience with online platforms is feeding back to television, which far from being replaced by online content is evolving alongside it towards "the creation of interactive experiences that support or enhance the television-watching experience and innovations" through both "technical and social research and experimentation." [Obrist et al., 2015, p. 34].

But the fact that the BBC clearly allocates a significantly larger and carefully selected workforce to their online channels than the other providers we interviewed seems to suggest that much more work is required to run an online video channel to its full potential, than the popularity and ease-of-use of platforms like YouTube may lead one to believe. Indeed, lack of time is the reason our other interviewees 
do not quite manage to take the same care of the features of online video related to interaction with the audience and community building, which however all agree to be fundamental to making it unique in science communication.

The creation of online communities had already been highlighted by Busse [2007] as a particular advantage of online video in science communication, with social media playing an essential role in building and supporting these communities. In fact, YouTube itself can be considered a social medium and its integration on other social platform expands its own reach even further. Our interviewees consistently acknowledged the importance of social media to promote viewings. Getting numbers of views is, however, just one part of the contribution that social media facilitate around online video. As stated by Obrist et al. [2015], "social media has changed the game of viewing experiences, not only expanding the personal viewing space beyond the physical limits, but also creating the opportunity for new services for viewer participation and engagement" [pp. 35-36]. This is especially noteworthy in a day and age in which high importance is given to two-way interaction with the public in science communication.

Limitations, conclusions and further research
As is inherent to an exploratory study with qualitative methods, no claim is being made regarding the generalisation of these results and, obviously, no statistical inference is intended with a sample size of 5 . However, qualitative methods allow us to establish a phenomenon and test hypotheses against additional data [Cummins, 1999; Cummins, 2009].

Our study has revealed not only fundamental differences and similarities between the online science video channel providers we explored but also how the essentially different and unique nature of online video as a science communication format that allows for interaction with viewers, is grasped and pursued to different degrees among them. In this regard, the BBC shows that building communities with which to establish and sustain a dialogue is central to their channels BBC Earth and BBC Earth Unplugged, and evidences an exceptional ability to see this through, to a great extent thanks to the significantly larger team behind the channel. Whilst it is true that one of the major innovations brought about by the advent of online video platforms such as YouTube is the possibility for anyone to upload videos of their own making, with very low production costs, this study suggests that a professional broadcaster like the BBC may be in a better position (i.e. have the resources) to lead the way in realising the full potential of online video, in particular regarding its use to introduce dialogue and the creation of a community with viewers, to a medium (video) that had hitherto been the paradigm of one-way science communication when broadcast over TV.

As stated by Obrist et al. [2015], research on online video and interactive TV is and will be looking at novel interaction concepts, among other aspects. In this regard, the the BBC and their channel Earth Unplugged stands out in this study as an interesting potential case study for further research on the mutual influence between online video and television.

Other themes that align with current research include the role of social media - or perhaps online video as part of social media - and the use of surprise in order to 
engage audiences. Our interviewees were in consistent agreement about the importance of these, providing further cases that can be taken into consideration as the basis and starting point of further research.

\section{References}

AbiGhannam, N., Kahlor, L., Dudo, A., Liang, M.-C., Rosenthal, S. and Banner, J. L. (2016). 'Expectancies and Motivations to Attend an Informal Science Lecture Series'. International Journal of Science Education, Part B 6 (3), pp. 215-238. DOI: $10.1080 / 21548455.2015 .1039468$.

Alexa (2015). The top 500 sites on the web. URL: http://www . alexa.com/topsites (visited on 7th March 2015).

Bruns, A. (2007). 'Produsage: Towards a Broader Framework for User-Led Content Creation'. In: Proceedings of the 6th ACM SIGCHI Conference on Creativity $\mathcal{E}$ Cognition. (Washington, DC, U.S.A.). DOI: 10.1145/1254960.1254975.

Burton, A. (2008). 'YouTube-ing your way to neurological knowledge'. The Lancet Neurology 7 (12), pp. 1086-1087. DOI: 10.1016/S1474-4422(08)70252-7.

Busse, M. (2007). 'Online video is transforming and broadening perceptions about science. The rise of video webcasting is bringing the trials and triumphs of science to a whole new audience'. New Scientist 195 (2612), pp. 26-27. DOI: $10.1016 / \mathrm{S} 0262-4079$ (07)61770-9.

Cha, J. and Chan-Olmsted, S. M. (2012). 'Substitutability between Online Video Platforms and Television'. Journalism \& Mass Communication Quarterly 89 (2), pp. 261-278. DOI: $10.1177 / 1077699012439035$.

Cisco (2014). Global 2016 forecast highlights. URL: http: //www . cisco. com/web/solut ions/sp/vni/vni_forecast_highlights/index.html (visited on 7th March 2015).

Cooper, D. and Higgins, S. (2015). 'The effectiveness of online instructional videos in the acquisition and demonstration of cognitive, affective and psychomotor rehabilitation skills: The effectiveness of online instructional videos'. British Journal of Educational Technology 46 (4), pp. 768-779. DOI: 10.1111/bjet. 12166.

Cummins, J. (1999). 'Alternative Paradigms in Bilingual Education Research: Does Theory Have a Place?' Educational Researcher 28 (7), pp. 26-41. DOI: $10.2307 / 1176138$.

- (2009). 'Transformative Multiliteracies Pedagogy: School-based Strategies for Closing the Achievement Gap'. Multiple Voices for Ethnically Diverse Exceptional Learners 11 (2), pp. 38-56. URL: http://multiplevoices journal .org/doi/abs /10.5555/muvo.11.2.2420352213232u47? journalCode=muvo.

DeCesare, J. A. (2014). 'The Expanding Role of Online Video in Teaching, Learning, and Research'. Library Technology Reports 50 (2), pp. 5-12.

Howitt, D. (2013). Introduction to Qualitative Methods in Psychology. Harlow, U.K.: Pearson.

Huang, J., Chen, R. and Wang, X. (2012). 'Factors influencing intention to forward short internet videos'. Social Behaviour and Personality 40 (1), pp. 5-14.

Kim, J. (2012). 'The institutionalization of YouTube: From user-generated content to professionally generated content'. Media, Culture $\mathcal{E}$ Society 34 (1), pp. 53-67. DOI: $10.1177 / 0163443711427199$.

Kousha, K., Thelwall, M. and Abdoli, M. (2012). 'The role of online videos in research communication: A content analysis of YouTube videos cited in academic publications'. Journal of the American Society for Information Science and Technology 63 (9), pp. 1710-1727. DOI: 10.1002/asi. 22717. 
Lister, M., Dovey, J., Giddings, S., Grant, I. and Kelly, K. (2009). New media: A critical introduction. London, U.K.: Routledge.

Morain, M. and Swarts, J. (2012). 'YouTutorial: A Framework for Assessing Instructional Online Video'. Technical Communication Quarterly 21 (1), pp. 6-24. DOI: $10.1080 / 10572252.2012 .626690$.

Obrist, M., Cesar, P., Geerts, D., Bartindale, T. and Churchill, E. F. (2015). ‘Online video and interactive TV experiences'. interactions 22 (5), pp. 32-37. DOI: $10.1145 / 2799629$.

Pace, B. G. and Jones, L. C. (2009). 'Teaching with Web-Based Videos: Helping Students Grasp the Science in Popular Online Resources'. Science Teacher 76 (1), pp. 47-50. URL: http://learningcenter.nsta.org/resource/default.aspx?i d=10.2505/4/tst09_076_01_47.

Pace, S. (2008). 'YouTube: an opportunity for consumer narrative analysis?' Qualitative Market Research: An International Journal 11 (2), pp. 213-226. DOI: 10.1108/13522750810864459.

Pandey, A., Patni, N., Singh, M., Sood, A. and Singh, G. (2010). 'YouTube As a Source of Information on the H1N1 Influenza Pandemic'. American Journal of Preventive Medicine 38 (3), e1-e3. DOI: 10.1016/j. amepre. 2009.11.007.

Pirouz, D. M., Johnson, A. R., Thomson, M. and Pirouz, R. (2015). 'Creating Online Videos That Engage Viewers'. Mit Sloan Management Review 56 (4), pp. 83-88.

Thelwall, M., Sud, P. and Vis, F. (2012). 'Commenting on YouTube videos: From guatemalan rock to El Big Bang'. Journal of the American Society for Information Science and Technology 63 (3), pp. 616-629. DOI: 10.1002/asi. 21679.

Trotha, C. Y. R.-v., Morcillo, J. M. and Czurda, K. (2016). Typologies of the popular science web video.

URL: https://jcom.sissa.it/archive/15/04/JC0M_1504_2016_A02.

Veal, A. J. (2011). Research methods for leisure and tourism: a practical guide. Harlow, U.K.: Financial Times Prentice Hall.

Welbourne, D. J. and Grant, W. J. (2015). 'Science communication on YouTube: Factors that affect channel and video popularity'. Public Understanding of Science 25 (6), pp. 706-718. DOI: 10.1177/0963662515572068.

Young, J. R. (2011). 'TED, Known for big-idea conferences, pushes into education'. The Chronicle of Higher Education.

URL: http://www . chronicle.com/blogs/wiredcampus/ted-known-for-big-id ea-conferences-pushes-into-education/30094 (visited on 19th November 2015).

YouTube (2013). YouTube Creator Playbook. URL: https://www . thinkwithgoogle.com/playbooks/youtube.html.

- (2015). YouTube trends. URL: http://youtube-trends . blogspot.co. uk (visited on 6th March 2015). 
M. Carmen Erviti obtained a Ph.D. in Communication Studies from the University of Navarra, Spain, where she currently is Assistant Professor at ISSA-School of Management Assistants, and carries out research with the School of Journalism as part of the team with special interest in Science Communication. M.C.E.'s work on this project was funded by the Spanish Ministry of Education, Culture and Sports (CAS14/00147). E-mail: mcerviti@unav.es.

Erik Stengler (corresponding author) is Senior Lecturer in Science Communication at the University of the West of England. His special interests in this area include Science Museums and Planetariums, Science in Film and, more broadly, how to succeed in communicating science to those not particularly interested in it.

E-mail: erik.stengler@uwe.ac.uk.

How to cite

Erviti, M. C. and Stengler, E. (2016). 'Online science videos: an exploratory study with major professional content providers in the United Kingdom'.

JCOM 15 (06), A06. 